\title{
Study on Fatigue Strength of Main Anti-collision Structure of Main Pier
}

\author{
Jifeng Wang ${ }^{1}$, Liangchao Guan ${ }^{2}$ and Jing Ge ${ }^{3, *}$ \\ ${ }^{1}$ Henan Province Transportation Development Center, Zhengzhou, Henan, China, 461099 \\ ${ }^{2}$ Henan Provincial Communications Planning \& Design Institute Co., Ltd., Zhengzhou, \\ Henan, China, 461099 \\ ${ }^{3}$ Jiangsu Hongyuan Science and Technology Engineering Co., Ltd., 801 Changwu Road, \\ Changzhou, Jiangsu, China, 213162
}

\begin{abstract}
In order to improve the efficiency of water transport, avoid energy waste and protect the environment of the ocean and river, the protection of large transport vessels is particularly important. With the continuous development of waterway regulation and the continuous improvement of navigation conditions, the number of ships sailing in the Yinzhouhu section is increasing, and the risk of bridges being hit by ships is also gradually increasing. There are two common ways of bridge anticollision: independent anti-collision system and its own anti-collision system. The former often adopts the form of independent anti-collision pier, which is generally used in the anti-collision area of old bridges, New bridges generally do not use this method, the latter mainly uses the method of improving the structural firmness of piers to achieve anti-collision, which is the most commonly used and more economical anti-collision method at present. In order to select a more reasonable standard of ship impact force and lay out reasonable anti-collision facilities, the anticollision facilities of left branch main pier $(55,56)$ and right branch main pier $(76,77)$ of ZhongKai Yinzhouhu super-large bridge are studied and designed to provide reference for bridge design.
\end{abstract}

\section{Introduction}

With the development of science and technology, the increasing demand of human life, marine pollution is becoming more and more serious. The production and operation of large transport ships are also increasing. In order to save energy, protect the marine environment from pollution and ensure the safety of human life and property, it is urgent to study the safety protection of large transport vessels. The advantages of water transportation are obvious[1-7]. First of all, the shipping cost is lower[8-10], the tonnage of shipping is larger, and the shipping cost and freight rate are lower than that of highway, so it has obvious advantages in bulk cargo transportation; Secondly, ship energy consumption is low[11-13]. Among all kinds of transportation modes, road transportation and civil aviation transportation are well-known transportation modes with low energy efficiency; Thirdly,

\footnotetext{
*Corresponding author: 497500373@qq.com
} 
with the rapid economic development of Zhongshan, Jiangmen and other places, and the continuous improvement of port facilities, the number of water transport ships will further increase. Affected by the above three factors, the number of ships will continue to increase in the future, and the risk of pier collision will gradually increase[14-17].

Pier is not only the basic engineering of traffic, but also the navigation obstructing structure of channel. Its anti-collision ability is the safety focus of land and water traffic[1821]. In order to protect the safety of ships and bridges, special research on bridge anticollision and anti-collision and impact safety risk assessment are carried out in complex waters and navigation areas, In order to improve the safety and reliability of the bridge engineering within the scope of reasonable cost and economic and reasonable bridge anticollision design, provide technical support for the ship navigation and the construction of the project itself during and after the bridge construction.

\section{Design of main pier of Yinzhouhu Bridge}

Zhongshan Kaiping expressway is an East-West Expressway planned by Zhongshan and Jiangmen to connect Hong Kong, Macao, Shenzhen, Zhongshan, the main urban area of Jiangmen, Kaiping and Taishan. The project is an extension of Shenzhong corridor in Zhongshan and the southern area of Jiangmen. Its construction is of great significance to improve the regional road network and relieve the traffic pressure of Jianghe and Jiangzhong expressways, It is of great significance to improve the road network structure of the expressway network on the West Bank of the Pearl River, which is strong in the northsouth direction and weak in the east-west direction, and to improve the single import and export situation in Shenzhen, Zhongshan, Jiangmen, YINZHOUHU, Kaiping, Taishan and Enping.

\subsection{Main pier of Zuocha Bridge}

The left branch is the main channel, and the intersection angle between the normal direction of the bridge axis and the flow direction is $3^{\circ}$, The span of the main bridge is $(58+160+$ $530+160+58) \mathrm{m}$, the cable-stayed bridge structure, and the clear distance between navigable hole caps is about $501 \mathrm{M}$. after considering the reservation of $5 \mathrm{~m}$ anti-collision facilities on each side, the navigable clearance width is $491 \mathrm{~m}$, the upper bottom width is $491 \mathrm{~m}$ consistent with the clear width, and the clear height is $48 \mathrm{M}$ as shown in Fig. 1.

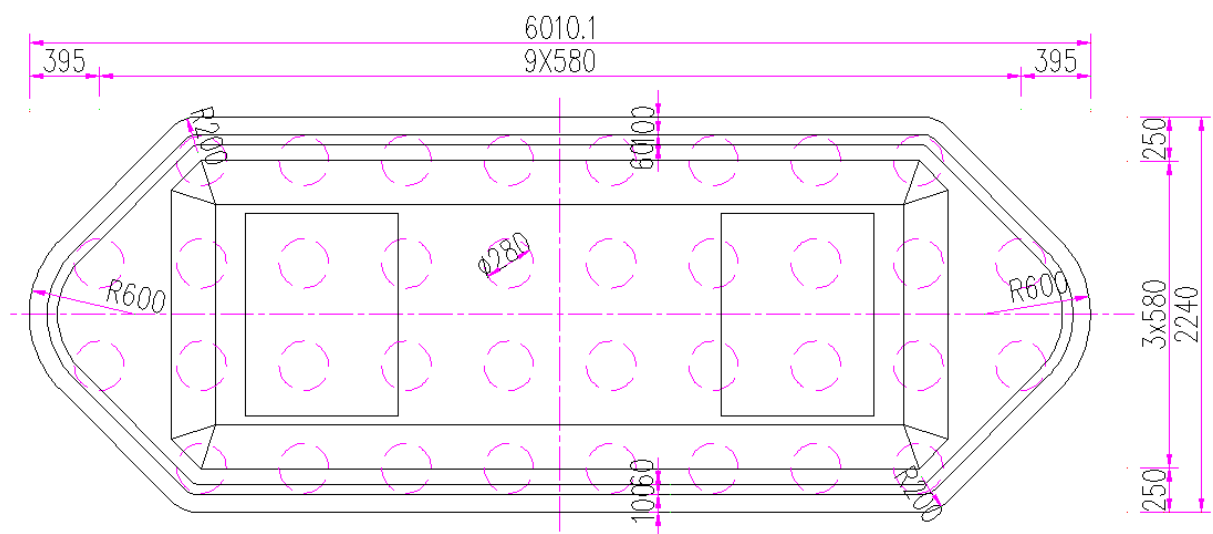

Fig. 1. Plan of main pier of zuocha Bridge 


\subsection{Main pier of Youcha Bridge}

The intersection angle between the normal direction of the right branch bridge axis and the flow direction is $3^{\circ}$, The span is $100+162+100 \mathrm{~m}$ continuous rigid frame structure, with single hole two-way navigation. The clear distance between navigation hole caps is $150 \mathrm{~m}$, and the navigation clearance width is $148 \mathrm{~m}$, the upper bottom width is $129 \mathrm{~m}$, the clear height is $18 \mathrm{~m}$, and the side height is $14 \mathrm{~m}$ after $1 \mathrm{~m}$ anti-collision facilities are reserved on each side as shown in Fig. 2.

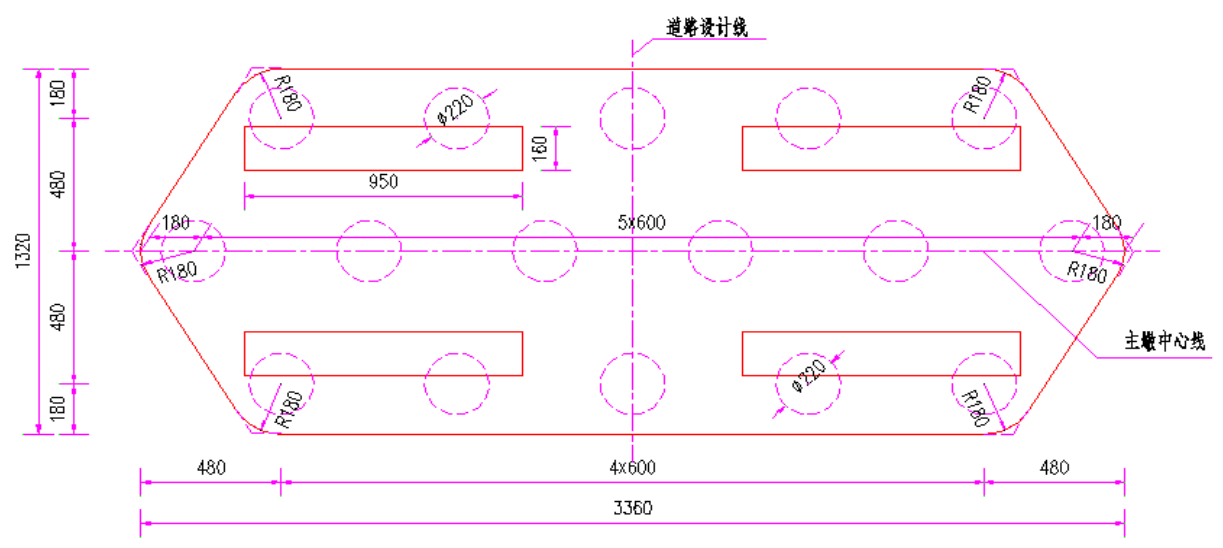

Fig. 2. Plan of main pier of Youcha Bridge

\section{Finite element analysis of bridge anti-collision facilities}

In this work, GeniE module, HydroD module, Sestra module and Submod module of SESAM software are used to analyze the overall structural strength of floating anticollision facilities. The panel model for hydrodynamic analysis and the structural model for strength check are created in Genie module.

When the draft of the anti-collision device is $2.0 \mathrm{~m}$, the drainage volume is about $864 \mathrm{t}$, of which the steel structure is about $330 \mathrm{t}$.

According to the structural characteristics, each module is connected by bolts, and the overall structure process is based on the overall connection, ignoring the influence of bolt connection as shown in Fig. 3.

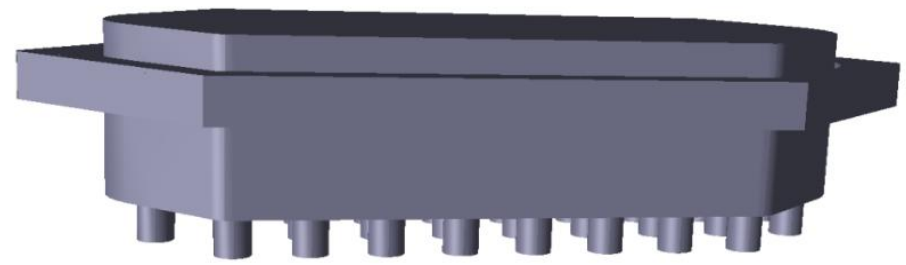

Fig. 3. Schematic diagram of main structure of bridge anti-collision facilities

The floating anti-collision facility is a new type of structure, there is no corresponding norms and standards for reference design. In this report, the yield strength, fatigue strength and buckling strength of the floating anti-collision facility structure are directly calculated and checked by conventional analysis method. For the structural strength analysis of floating anti-collision facilities, the direct calculation method is used to constrain. 
The structural strength of floating anti-collision facilities is checked by finite element method, and the finite element model is built in the genie module of SESAM finite element software. The 4-node quadrilateral element and 2-node beam element are used for modeling, in which the main mesh size is $0.8 \mathrm{~m}$; The number of grid cells is 43150 and the number of nodes is 92022 in the structure and cell grid of each part in the single module of anticollision facilities.

Fig. 4 shows the hydrodynamic analysis model of anti-collision facilities. The main unit is a four node quadrilateral unit with 5683 units; The design draft is $2.0 \mathrm{~m}$.

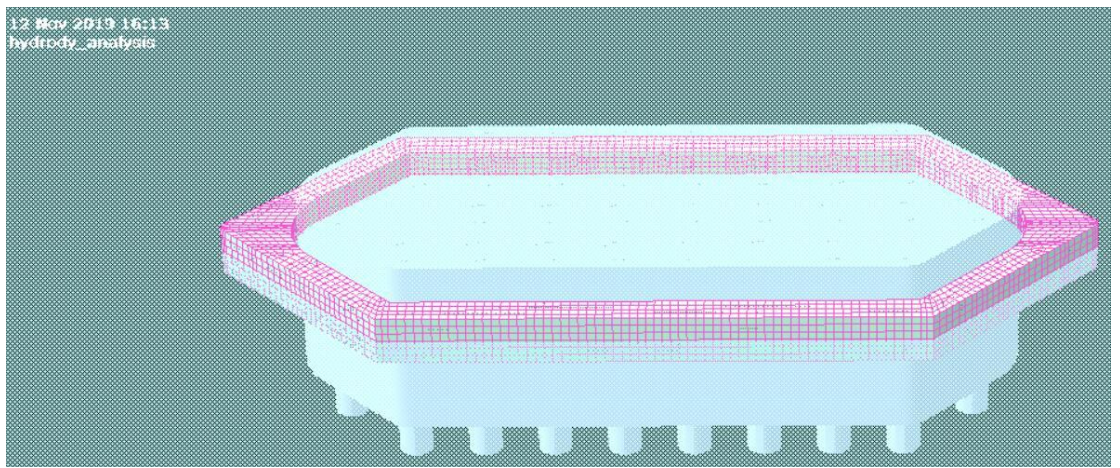

Fig. 4. Hydrodynamic finite element analysis

In the process of analysis, considering the function of anti-collision cushion, spring constraint is used at the position of anti-collision cushion, and the constraint direction is translation in $\mathrm{X}, \mathrm{y}$ and $\mathrm{Z}$ directions, and the rotation is released.

For the analysis area, the finite element model is created, in which the angle steel is created by plate element; The main element type is 8-node shell element, and the establishment of finite element model is shown in the figure below.

In order to better transfer the stress in the overall structure model to the fatigue strength analysis area, the sub model method is adopted, taking the displacement and deformation of the overall structure as the boundary of the sub model, and considering the wave load of the sub model, the corresponding wet surface element is established, as shown in Fig. 5.

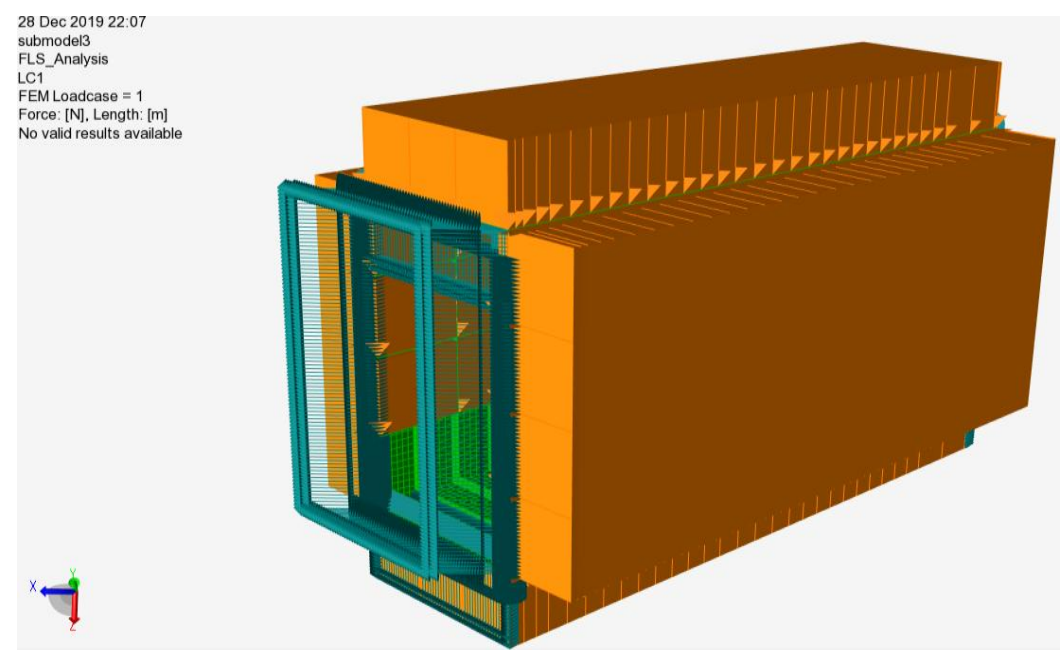

Fig. 5. Finite element model of wave loaded wet surface in Zone IV of fatigue strength analysis area 


\section{Conclusions}

In this work, the structural fatigue strength of floating anti-collision facilities is analyzed and checked by SESAM software. Through the analysis of the structure fatigue strength, the following conclusions can be obtained

1) The structure layout is greatly affected by the wave direction and occurrence probability, so the wave environmental conditions should be fully considered in the layout of anti-collision protection structure;

2) The fatigue life of most internal bone materials is much longer than 20 years, but there is obvious stress concentration at the joint of bone materials; It is necessary to increase the elbow plate in this area, which is also necessary to be added in the relevant structural specifications of marine structures such as ships.

3) The fatigue life of most internal plates is much longer than 20 years due to the boundary constraint effect; The fatigue life at the boundary is less than 20 years, which is mainly due to the finite element analysis method and can be ignored.

4) Most of the design life of the outer plate structure can be more than 20 years, but in the arc transition area, the structure needs to be strengthened, such as increasing the plate thickness or increasing the size and density of the internal bone.

This work provides strong security and guidance for water transportation. It provides theoretical basis and practical significance for protecting marine and river environment from pollution and improving transportation efficiency.

\section{Acknowledgement}

This work was financially supported by the Science and Technology Project of Henan Transportation Department of China (Grant No. 2017J3), and the Changzhou Science and Technology Support Plan (industry) of China (CE202000009).

\section{References}

[1] G. Yu, C. Du, T. Sun. Thermodynamic Behaviors of a kind of Self-Decoupling Magnetorheological Damper. Shock and Vibration. 2015, Article Number: 502747.

[2] S. Mazlan, I. Ismail, H. Zamzuri, et al. Compressive and tensile stresses of magnetorheological fluids in squeeze mode. Int J App Electrom Mech, 2011(4), Vol.36:327-337.

[3] A. Olabi, A. Grunwald. Design and application of magneto-rheological fluid. Material \& Design, 2007(10), Vol.28:2658-2664.

[4] H. Jiang, J. Ge, G. Yu, B. Su, T. Sun. Study on Radial, Axial and Shear Mechanics Properties of Single-walled Carbon Nanotubes by Finite Element Analysis. Journal of Computational and Theoretical Nanoscience. 2017(6), Vol.14:P2596-2600.

[5] J. Ge, C. Jiang, G. Yu, B. Su, T. Sun. Preparation and Research on a Kind of Magnetorheological Grease Materiel Used Anti-Collision System. Materials Science Forum. 2017, Vol.893:P395-399.

[6] Y. Wang, Q. Luo, H. Liu, et al. Aggregated chain morphological variation analysis of magnetorheological fluid (MRF) in squeeze mode. Smart Material an Structures, 2019(10), Vol.28:1-9.

[7] D. Li, D. Keogh, D. Huang, et al. Modeling the Response of Magnetorheological Fluid Dampers under Seismic Conditions. Applied Sciences-Basel, 2019(19), Vol.9:4189.

[8] Y. Liang, J. Alvarado, K. Iagnemma, et al. Dynamic Sealing Using 
Magnetorheological Fluids. Physical Review Applied, 2018(6), Vol.10.

[9] Z. Tian, X. Wu, X. Xiao, et al. Influence of Temperature on Torque Transmission Stability of Magnetorheological Fluid. Journal of Magnetics, 2018(4), Vol.23:529-535.

[10]H. Seugyong, K. Kwanglok, K. Kwangmin, et al. 45.5-tesla direct-current magnetic field generated with a high-temperature superconducting magnet. Nature. 2019, Vol.570:496-499.

[11]X. Xu, W. Koshebae, Y. Tokunaga, et al. Transformation between meron and skyrmion topological spin textures in a chiral magnet. Nature. 2019(7743), Vol.564.

[12]I. Belopolski, K. Manna, D. Sanchez, et al. Discovery of topological Weyl fermion lines and drumhead surface states in a room temperature magnet. Science.2019(6459), Vol.365:1278.

[13]T. Kurumaji, T. Nakajima, M. Hirschberger, et al. Skyrmion lattice with a giant topological Hall effect in a frustrated triangular-lattice magnet. Science. 2019(6456), Vol.365:914-919.

[14]R. Ahamed, SB. Choi, M. Ferdaus, et al. A state of art on magneto-rheological materials and their potential applications. Journal of Intelligent Material System and Structures, 2018(10), Vol.29:2051-2095.

[15]H. Wang, G. Zhang, J. Wang, et al. Normal force of lithium-based magnetorheological grease under quasi-static shear with large deformation. Rsc Advances, 2019(47), Vol.9:27167-27175.

[16] J. Ge, H. Jiang, Z. Sun, G. Yu, B. Su, T. Sun. Calculating Mechanics Characteristics of Single-walled Carbon Nanotube Materials by Finite Element Method. Key Engineering Materials. 2017, Vol.730:P548-553.

[17] X. Zhang, R. Wu, K. Guo, et al. Dynamic characteristics of magnetorheological fluid squeeze flow considering wall slip and inertia. Journal of Intelligent Material System and Structures, 2019, Article Number: UNSP 1045389X19888781.

[18]T. H. Sun, J. Ge, Z. Jia, N. Huang. Preparation of Magnetorheological Greases and Study Their Rheological Characteristics Considering the Variety of Factors. International Journal of Materials Engineering. 2019(2), Vol.9:P34-38.

[19] H. Wang, Y. Li, G. Zhang, et al. Effect of temperature on rheological properties of lithium-based magnetorheological grease. Smart Materials and Structures, 2019(3), Vol.28, Article Number:035002.

[20] J. Zheng, Y. Li, J. Wang, et al. Accelerated thermal aging of grease-based magnetorheological fluids and their lifetime prediction. Materials Research Express, 2018(8), Vol.5, Article Number:085702.

[21] T. H. Sun, J. Ge, K. Tan, Y. Wu, Z. Jia, Y. Chen, C. Liu. Research on the Mechanism of a Thermistor-type Electronic Thermostat. International Journal of Innovative Studies in Sciences and Engineering Technology. 2019(12), Vol.5: P34-37. 